\title{
NOTAS SOBRE A EDUCAÇÃO POR TECNOLOGIAS DIGITAIS DA INFORMAÇÃO E COMUNICAÇÃO NA PANDEMIA DA COVID-19 À LUZ DA GEOGRAFIA
}

Tairan Barbosa de Oliveira ${ }^{1}$

\section{Resumo}

O presente trabalho desenvolve uma análise da educação escolar na sociedade brasileira, na perspectiva das Tecnologias Digitais da Informação e Comunicação (TDICs) utilizadas na educação no contexto de isolamento social decorrente da pandemia da Covid-19 a partir da Geografia, que cumpre função fundamental para compreensão das dinâmicas espaciais como lócus do processo social. Para tanto, dentro dos limites deste trabalho, realizou-se apreciação de atributos do sistema de educação brasileiro desde aspectos gerais normativos, perfil comum da infraestrutura à sistemática de monitoramento da educação, com vistas ao entendimento da função escolar. Por conseguinte, foram expostas características da forma de uso das TDICs na sociedade e na educação brasileira, relacionadas ao modelo de cidadania instituída pelo Estado que define os objetivos da educação.

Palavras-chave: Educação. TDICs. Geografia.

\section{NOTES ABOUT EDUCATION BY INFORMATION AND COMMUNICATION DIGITAL TECHNOLOGIES IN THE COVID-19 PANDEMIC IN THE LIGHT OF GEOGRAPHY}

\begin{abstract}
The present work develops an analysis of school education in Brazilian society, from the perspective of Information and Communication Digital Technologies (ICDTs) used in education in the context of social isolation resulting from the Covid-19 pandemic from Geography, which plays a fundamental role in understanding of spatial dynamics as the locus of the social process. For this purpose, within the limits of this work, an appreciation of attributes of the Brazilian education system was carried out, from general normative aspects, a common infrastructure profile to the education monitoring system, with a view to understanding the school function. Consequently, characteristics of the way of using ICDTs in Brazilian society and education were exposed, related to the model of citizenship instituted by the State that defines the objectives of education.
\end{abstract}

Keywords: Education. Geography. Technologies.

\footnotetext{
${ }^{1}$ Mestre em Geografia pela Universidade Federal de Alagoas na linha de pesquisa Organização Socioespacial e Dinâmicas Territoriais do Instituto de Geografia, Desenvolvimento e Meio Ambiente (IGDEMA). Email: 13tairan@gmail.com
} 
Notas sobre a educação por tecnologias digitais da informação e comunicação na pandemia da covid-19 à luz da geografia

\section{NOTAS SOBRE LA EDUCACIÓN MEDIANTE TECNOLOGÍAS DIGITALES DE LA INFORMACIÓN Y LA COMUNICACIÓN EN LA PANDEMIA COVID-19 A LA LUZ DE LA GEOGRAFÍA}

\section{Resumen}

El presente trabajo desarrolla un análisis de la educación escolar en la sociedad brasileña, desde la perspectiva de las Tecnologías Digitales de la Información y la Comunicación (TDICs) utilizadas en la educación en el contexto de aislamiento social resultante de la pandemia Covid19 de la geografía, que juega un papel fundamental en comprensión de la dinámica espacial como locus del proceso social. Para ello, dentro de los límites de este trabajo, se llevó a cabo una apreciación de los atributos del sistema educativo brasileño, desde aspectos normativos generales, un perfil de infraestructura común al sistema de monitoreo educativo, con miras a comprender la función escolar. En consecuencia, se expusieron características de la forma de uso de los TDICs en la sociedad y la educación brasileñas, relacionadas con el modelo de ciudadanía instituido por el Estado que define los objetivos de la educación.

Palabras clave: Educación. TDICs. Geografía.

\section{INTRODUÇÃO}

Neste trabalho, tentou-se analisar o modelo de educação decorrente da forma como a globalização tem organizado a sociedade brasileira, que embora venha sendo formada ao longo do período capitalista de organização econômica, nas últimas cinco décadas está caracterizada pela intensa conexão entre os lugares, possível, antes de mais nada, pela capacidade tecnológica que o mundo desenvolveu de transmitir informações, fazendo-nos entender que se trata de um novo paradigma, de uma sociedade que se espacializa e redefine os espaços com técnicas de informação, processo ao qual Milton Santos definiu como "meio técnico-científicoinformacional" (SANTOS, 2008a, p. 238). E os pedagogos identificam como sociedade da informação, ou ainda, sociedade da aprendizagem, pela capacidade de produção, reprodução e difusão de informações.

O que se tem então, nessa perspectiva, é uma sociedade que reflete diretamente na forma como o sistema de educação se organiza e como a escola precisa se organizar (DOWBOR, 2001). Porque o sistema educacional é um produto do tipo de sociedade, da forma de governo e da organização do Estado, dos elementos culturais, políticos e econômicos que constroem a sociedade e, consequentemente, envolvem a educação (GARCIA; YANNOULAS, 2017).

Nesse sentido, é preciso entender os elementos que definem o modelo de educação vigente e avaliar se atende às necessidades sociais, especialmente em um contexto de 
isolamento social, que ora atravessamos decorrente da pandemia provocada pela Covid-19. Partindo dessa premissa, desenvolveu-se uma breve investigação sobre a função que a escola vem desempenhando e a ação docente a reboque dessa função. Essa reflexão apoiou-se, em considerações sobre a estrutura comum do acesso à educação pública brasileira, ou seja, aspectos materiais e normativos que definem o tipo de educação que se desenvolve, níveis de exigência e o que se alcança como retorno social.

Em seguida, foi necessário efetuar um exame que pudesse, dentro dos limites desse estudo, dar alguma resposta ao problema fundamental que se desenvolveu na reflexão inicial. Essa análise foi guiada pela apreensão de dados que avaliam o acesso da população brasileira às Tecnologias Digitais da Informação e Comunicação (TDICs), em que foi possível identificar a densidade e rarefação dessas tecnologias no território brasileiro, principalmente através de mapa e gráfico.

Partindo do entendimento que, de uma forma geral, o sistema de educação tem servido a um processo de legitimação dos problemas que afligem a sociedade e retardam o desenvolvimento social, realizou-se uma reflexão apoiada em autores que desenvolveram reconhecidas compreensões sobre a importância do sistema de educação para a sociedade contemporânea. A partir da ideia de que o tipo do conjunto de técnicas modela o desenvolvimento social (ORTEGA Y GASSET, 1963) e a reprodução social (DOWBOR, 2001 e 2013), verificou-se aspectos do sistema de educação e da prática docente (DURKHEIM, 2011; FREIRE, 1987; PERRENOUD, 2000; SAVIANI, 2010 e 2013), que sofrem influência do modelo socioeconômico. Essa influência se dá de diferentes maneiras, de metodologias de avaliação, constatadas através de instituições e órgãos nacionais e globais que fiscalizam, monitoram e ditam regras sobre a escolarização, aqui analisadas. Também na concepção de cidadania normatizada pelo Estado capitalista e legitimada pela escolarização a serviço do modelo economicista de desenvolvimento social vigente (GARCIA; YANNOULAS, 2017; DOWBOR, 2013; MÉSZAROS, 2008; SANTOS, 1997 e 2012).

Para isso, o trabalho teve como objetivo geral, realizar uma análise da educação em face do uso das TDICs, confrontada pela Covid-19, à luz da geografia. Buscou-se ainda, identificar o perfil geral da estrutura da educação, entender a relação das TDICs com o sistema de educação e verificar a distribuição espacial das TDICs utilizadas na educação. Dessa forma, foi possível discorrer sobre como a educação e as TDICs da sociedade contemporânea podem definir um modelo de educação capaz de mudar a sociedade. Isso decorre da capacidade que se 
Notas sobre a educação por tecnologias digitais da informação e comunicação na pandemia da covid-19 à luz da geografia

desenvolveu de conectar lugares que se comunicam e distribuem informações de forma intensa e difusa. Esse processo é possível pela capacidade tecnológica que se instalou no espaço.

\section{UMA REFLEXÃO SOBRE A FUNÇÃO DA ESCOLA E A AÇÃO DOCENTE}

Em uma linha de entendimento, a ideia de técnica é a de que se refere ao processo ou ao conjunto de ferramentas e ações que constitui uma forma de realização do desenvolvimento social. No sentido em que a técnica é aquilo que promove um retorno social, que envolve um conjunto de procedimentos, instrumentos e ações, que permitem ao ser humano desenvolver o trabalho que busca melhorar as condições materiais de vida (ORTEGA Y GASSET, 1963).

Nesse sentido, o sistema de educação formal, normatizado e realizado em última instância, por estabelecimentos educacionais - as escolas - pode ser entendido como uma técnica. Uma forma de produção e reprodução social.

A escola nessa perspectiva é um reflexo do tipo de sociedade, pois representa ao mesmo tempo uma ferramenta de reprodução social (DOWBOR, 2001, p. 11) e um produto do processo histórico da humanidade. E no período atual, essa complexidade se expande, dada a globalização, que intensifica aspectos locais e impõe aspectos globais dos fenômenos sociais ao cotidiano, desde elementos de ordem econômica, cultural e política. Estes, por sua vez, são tutelados pela economia capitalista que influencia a sistematização da educação na normatização e na prática educacional, que decorre da forma como o Estado institui a regulamentação, a supervisão, fiscaliza e mantém o sistema de educação. Dessa forma, o produto não é somente histórico, mas também geográfico, dado elementos elencados acima, circunscritos no território, como ocorre no estado de Alagoas, acolhido como recorte espacial para este estudo.

Isso decorre de que tanto a infraestrutura das escolas quanto o conjunto normativo conservam a identidade da Revolução Industrial brasileira ${ }^{2}$ que demandou a implantação de estabelecimentos de instrução pública. Ou seja, o modelo de escola atual ainda carrega consigo forte identificação com o modelo de escola de cerca de um século ${ }^{3}$.

O estudo Effective Teacher Policies do Programme for International Student Assessment (PISA) aponta que, no Brasil, as salas de aulas das escolas públicas, têm lotação excessiva e que a média de alunos por professores é a segunda maior entre os países analisados

2 Ciclo marcado pelas políticas dos governos de Getúlio Vargas 1930-1945; 1951-1954.

3 Pode-se entender que de forma geral a estrutura de educação universalizada pelo Estado nos países de democracia liberal, tem uma tradição funcionalista bastante inspirada em Émille Durkheim (2011). 
(OECD, 2018, p.26). Consequentemente, há limitações de equipamentos e suprimentos da possibilidade de aporte tecnológico aplicados à educação.

Salas aclimatadas, salas informatizadas, espaços de recreação, estúdio de arte, áreas esportivas e auditório é privilégio de poucas escolas, não é o padrão. Um misto de - por força da normatização e das condições físicas escolares - educação bancária (FREIRE, 1987) com currículos orientados por tendências pedagógicas desenvolvimentistas da economia capitalista, condicionadas por políticas governamentais fundamentalmente liberais e práticas neoliberais.

Essas condições estruturais, bastante comuns na rede pública brasileira dificulta a criação de um ambiente de aprendizagem e impõe muita dificuldade ao desenvolvimento do processo ensino/aprendizagem. São ambientes escolares desinteressantes para os jovens, tanto do ponto de vista da infraestrutura (SOARES; SÁTYRO, 2008) quanto do curricular (COSTA, 2010), tendo em vista ainda que a didática pode estar condicionada pela infraestrutura.

As pessoas estão em constante contato com tecnologias digitais dinâmicas e interativas do atual paradigma tecnológico. Ao chegarem na escola, se deparam com escolas repletas de problemas de infraestrutura, sem incorporação das TDICs ao processo ensino/aprendizagem e com professores forçados a utilizarem, na maior parte do tempo, apenas o livro didático quando este está disponível.

Note-se a Base Nacional Comum Curricular (BNCC) dar ênfase a procedimentos orientados às habilidades e competências (PERRENOUD, 2000) em detrimento do desenvolvimento científico, artístico, filosófico e antropológico, com vistas ao conhecimento clássico para o desenvolvimento humano (SAVIANI, 2013, p. 13). Reforçando o fundamento liberal de que a escola-educação tem que preparar o indivíduo para o "mercado de trabalho", suplantando a necessidade do desenvolvimento humano e universal. "O valor da educação expressa-se como promoção humana" (SAVIANI; DUARTE, 2010, p. 423).

No bojo da globalização, os currículos e parâmetros que definem o sistema de educação tendem cada vez mais a uma tentativa de homogeneização e alinhamento com países que lideram a economia de mercado mundial. É dessa forma, por exemplo, que o índice global mais utilizado como referência para medir a qualidade do ensino básico é o PISA criado pela Organisation for Economic Co-operation and Development (OECD) que, por sua vez, teve origem após a II Guerra Mundial para administrar o Plano Marshall. Outro índice bastante utilizado é o Índice de Desenvolvimento Humano da Organização das Nações Unidas. O IDH verifica as médias de renda per capta, expectativa de vida e tempo de escolaridade. 
Notas sobre a educação por tecnologias digitais da informação e comunicação na pandemia da covid-19 à luz da geografia

Embora esses índices sejam importantes para efeito de constatação, possuem metodologias que idealizam na educação a resolução de problemas socioeconômicos e forçam os países a se adequarem aos parâmetros exigidos pelos líderes do Produto Interno Bruto mundial e relativizam a profunda desigualdade no território Brasileiro.

Essa pressão para alcançar médias dos países economicamente desenvolvidos provoca efeitos na dinâmica escolar brasileira que precisam ser compreendidos. A desigualdade socioeconômica do Brasil se reflete nas diferenças entre as escolas, mesmo entre as redes públicas e dentro das redes, que estão condicionadas por políticas de governo, e apresentam disparidades de condições. Conforme aponta o denso estudo de Carlos A. C. Ribeiro (RIBEIRO, 2011), a educação no Brasil apresenta um conjunto complexo de diferentes fatores de desigualdades educacionais: classe econômica, cor da pele, região de origem, escola frequentada antes da transição de nível, do tipo de transição, entre outras. Apresentando análises diversas que cruzam dados específicos como características da organização familiar (ibid., p. 72), o autor demonstra a relação "desigualdade de oportunidades educacionais (DOE)" e "desigualdade de resultados educacionais (DRE)" entrelaçadas pelas características sociais brasileiras.

A contradição se instala, tendo em vista que os índices e testes de verificação da aprendizagem estão padronizados e tentam homogeneizar, enquanto há disparidades no desenvolvimento da educação escolar, consequência das contradições sociais expressa nos lugares. A pobreza no Brasil é uma questão estrutural e não apenas de caráter individual ou capacidade cognitiva e a educação é um elemento da estrutura e não pode ser responsabilizada pela erradicação da pobreza (GARCIA; YANNOULAS, 2017).

A desigualdade socioeconômica do Brasil se desdobra no território, como no estado de Alagoas, onde o Índice de Gini do rendimento domiciliar per capita de 2017 foi de 0,530 (PNAD, 2018) - o índice varia de 0 a 1, em que 0,5 já é considerado profundamente desigual. A condição familiar influencia na condição educacional do estudante e na permanência do aluno na vida escolar.

Para efeito de constatação, a taxa 13,8\% de abandono/evasão escolar no ensino médio em Alagoas é mais que o dobro da brasileira (INDICADORES BÁSICOS DE ALAGOAS, 2017, p. 35). Podem ser vários os motivos disso, mas o principal é a condição socioeconômica, ou seja, até os 17 anos de idade o jovem abandona a escola pública pela urgência da sobrevivência. O Relatório SAEB 2017 (2019, p. 115) através do Indicador de Nível 
Socioeconômico das Escolas (INSE ${ }^{4}$ ) mostra que mesmo entre alunos da rede pública em todo o Brasil, há grande diferença nos resultados de proficiência em matemática e língua portuguesa. Ou seja, alunos que frequentam a mesma escola, mas que estão em circunstâncias sociais diferentes, têm resultado escolar muito diferente. Note-se ainda que tanto a pontuação (proficiência) alagoana quanto a brasileira são muito baixas, mantendo o ciclo da desigualdade e perpetuando a estrutura tanto em escala local quanto global.

Nesse meio estão os professores. A profissão docente não é simplesmente tecnicista, é vocacional e os docentes têm que lidar com questões que vão além da didática e da construção de conhecimento. "A educação, tanto em sua expressão geral como em sua forma escolar, compõe a ordem social e, portanto, reflete as tensões, os conflitos e as contradições dessa ordem social" (GARCIA; YANNOULAS, 2017, p. 24). Na escola, no ensino de massa, se somam problemas socioeconômicos, individuais, diferenças culturais e se concentra a diversidade de questões particulares. Ao docente, se impõe questões para além da sua área científica.

A profusão cultural pela qual a sociedade contemporânea se define, a qual a escola integra, decorre da capacidade que se desenvolveu de conectar lugares que se comunicam, produzem e distribuem informações de forma intensa e difusa. Esse processo é possível pela capacidade tecnológica que se instalou no espaço.

O espaço, o meio geográfico, se tornou um meio técnico-científico-informacional (SANTOS, 2008a, p. 238), pela densidade de objetos que atendem a uma lógica global que coloca os lugares em sintonia com as demandas hegemônicas econômicas, culturais e políticas.

As TDICs aplicadas à educação são as ferramentas do meio digital (codificação binária/informática), ou seja, microcomputador, Internet, smartphone, projetor multimídia, software, etc. Dessa forma, na perspectiva do meio geográfico contemporâneo, o "meio técnico-científico-informacional" - sistema de objetos e ações (SANTOS, 2008a), constituem os fixos e fluxos que conformam o ciberespaço. Essa configuração socioespacial emerge da difusão territorial dessas tecnologias que vêm a reboque do processo de globalização. Processo de globalização esse que é potencializado pela capacidade do território em absorver e desenvolver novas técnicas, especialmente as baseadas em tecnologias digitais representação de dados, hardware e software, comunicação e redes (CIEB, 2018).

Diante disso, a análise do aporte técnico permite identificar dinâmicas no território em conformação com o sistema econômico. Nos países subdesenvolvidos o espaço não acolhe as

4 O INSE, através dos formulários de respostas dos alunos nas avaliações da educação organizadas pelo Governo Federal, classifica sete níveis socioeconômicos dos alunos. Esses níveis procuram captar dados sobre a posse de equipamentos domésticos e acesso a serviços que demonstrem a condição socioeconômica do aluno. 
Notas sobre a educação por tecnologias digitais da informação e comunicação na pandemia da covid-19 à luz da geografia

variáveis modernas ao mesmo tempo, mostrando-se bastante seletivo. "A cada modernização, novos pontos ou novas zonas são conquistadas ao espaço neutro e tornam-se uma nova porção de espaço operacional”' (SANTOS, 2008b, p. 20). Conforme Pierre Lévy (LÉVY, 2010, p. 178), "as performances industriais e comerciais das companhias, das regiões, das grandes zonas geopolíticas, são intimamente correlacionadas a políticas de gestão do saber”. Decerto, a ideia de modernização não traduz necessariamente desenvolvimento, tendo em vista que modernização é a generalização completa de uma inovação vinda de um período anterior ou da fase imediatamente precedente. Contudo, em termos gerais, o nível de desenvolvimento e as condições de sobrevivência são dependentes dos progressos tecnológicos. Todavia, as desigualdades provocadas pelo sistema econômico fazem com que se criem no espaço zonas e setores decorrentes do desenvolvimento desigual e combinado (TROTSKY, 2017), como ocorre com a educação.

Essa densidade de objetos que se comunicam e que permitem a rapidez e abrangência de informações tirou da escola a exclusividade da concentração da informação que gera conhecimento nos lugares. Mas essa infraestrutura social é desigual e desigualmente incorporada à infraestrutura pedagógica. A escola é sinônimo de fonte do conhecimento científico, o professor seu ícone e a educação seu legado social. A educação é, possivelmente, a principal técnica de evolução social.

O docente, embora tenha alguma autonomia, trabalha numa estrutura onde as normas, parâmetros, ferramentas e infraestrutura escolar demostram que o sistema educacional brasileiro, mesmo alcançando as massas, ainda é elitista (FERREIRA JR., 2010). Não é um sistema desajustado, ao contrário, é sutilmente ajustado para a manutenção do status quo da realidade de desigualdade e de concentração econômica (SOUZA, 2018). A análise dos Microdados do ENEM 2005-2019 (INEP, 2020) revela que as escolas com melhores desempenho - proporção de alunos que realizaram o teste e melhores notas - são as privadas e públicas Federais.

A doutrina, incutida na sociedade, do sucesso financeiro e do desenvolvimentismo econômico como objetivo supremo do indivíduo e do Estado se desenrola na educação como promessa de um futuro melhor. Nesse sentido, o docente e a escola são o ponto de partida para o sucesso almejado. No imaginário social o docente é a personificação da educação. É a eles que as pessoas se direcionam e neles que o sistema educacional se apoia drenando sua energia, lhe impondo cargas de pressão social e burocracia. 
Note-se o que versa o guia Tecnologias na educação: ensinando e aprendendo com as TIC do Programa Nacional de Formação Continuada em Tecnologia Educacional - Proinfo Integrado, do Governo Federal, onde estão racionalizadas as demandas de desempenho aos professores enfatizando que,

Salgado (2003) diz que o docente tem uma tripla dimensão da identidade profissional. A qual "podemos, hoje, distinguir na identidade do profissional da educação três dimensões inseparáveis, pois ele é simultaneamente: um especialista que domina um instrumental próprio de trabalho e sabe fazer uso dele; um pensador capaz de repensar criticamente sua prática e as representações sociais sobre seu campo de atuação; um cidadão que faz parte de uma sociedade e de uma comunidade". Essa tripla dimensão da identidade docente, apontada pela autora, leva-nos a pensar que os educadores nos dias atuais precisam: ter domínio do conteúdo de sua área; entender os processos de aprendizagem dos alunos; saber ensinar, criando situações que favoreçam o aluno a encontrar sentido para aquilo que está aprendendo; conhecer e saber usar as tecnologias disponíveis no sistema escolar. E entender as implicações do uso das tecnologias e mídias nos processos de ensino e de aprendizagem (TORNAGHI, 2010, p. 41).

Há uma sobrecarga muito grande sobre o docente, normatizada e doutrinada pelo Estado e legitimada por profissionais e especialistas, sistematizada na educação fruto do tipo de sociedade regida pelo modelo de sistema econômico. Esse excesso de missões atribuídas aos professores e escolas fere a dignidade docente e do indivíduo.

Como resultado desse modelo de normatização e da pressão e projeção social sobre a prática docente e a escola, os professores têm sido forçados a se dedicarem e se preocuparem mais com tarefas burocráticas e pedagógicas que possam dar respostas estimulantes a esta expectativa socioeconômica - também para proteção pessoal e profissional -, do que refletir e desenvolver relações ensino/aprendizagem que possam contribuir para superar essa lógica de reprodução social orientada pelo sistema econômico vigente.

A educação como técnica de desenvolvimento social é transformadora e pode ser elemento revolucionário. Esse quadro de alienação provocada, precisa ser questionado e nos fazer indagar quais as necessidades humanas da educação, qual a função da escola e qual deve ser a ação docente no conjunto daquilo que a educação deve ser para uma sociedade?

\section{AS NECESSIDADES DA EDUCAÇÃO E O CONTEXTO DE PANDEMIA}

A recente popularização da Internet e do smartphone criou uma ideia de inclusão digital apenas a partir da generalização do acesso a essas tecnologias sem se verificar a diversidade das condições e dos níveis das ferramentas e serviços dessas TDICs. Assim, a comunicação 
Notas sobre a educação por tecnologias digitais da informação e comunicação na pandemia da covid-19 à luz da geografia

depende para manter relações educacionais de nível satisfatório. Além disso, inovação tecnológica é uma constante que em certo sentido, diverge da capacidade da população em possuir essa inovação e nesse aspecto, mantém o ciclo de desigualdade. Na verdade, o isolamento social decorrente da pandemia provocada pela Covid-19 escancarou e aprofundou as desigualdades de desenvolvimento educacional, especialmente com relação às TDICs.

Os dados de 2018 da Pesquisa Nacional por Amostra de Domicílios (PNAD, 2019) mostram que $67,1 \%$ dos domicílios no estado de Alagoas possuem conexão à Internet e que apenas 33,6\% dos domicílios possuem microcomputador. No Brasil 79,1\% dos domicílios têm conexão com Internet, sendo $83,8 \%$ na zona urbana, mas apenas $49,2 \%$ na zona rural - os dados desta diferenciação de áreas não estão disponíveis para os estados.

A $31^{\circ}$ Pesquisa Anual do Uso de TI nas Empresas do Centro de Informação Aplicada da Fundação Getúlio Vargas (FGVcia) sobre uso de tecnologias da informação, aponta que no Brasil há uma média de "dois dispositivos digitais por habitante", entre microcomputador, tablet e smartphone (FGV, 2020, p. 23). E 234 milhões de smartphones. A coleta de dados da pesquisa é feita a partir de empresas por formulários para as pessoas vinculadas a essas empresas, dentre as quais “66\% das 500 maiores". Todavia, a PNAD 2018 revela que 79,3\% da população brasileira possui telefone móvel de uso pessoal, além disso $98,1 \%$ dos smartphones são utilizados para acessar Internet e que 74,7\% da população acessa Internet (PNAD, 2019). Pode-se entender que em relação à PNAD, a pesquisa da FGV revela uma concentração desses equipamentos (TDICs) em um nicho da população.

Destarte, revela-se a rarefação de TDICs no território, a precariedade e as limitações no desenvolvimento da educação. Esse é o quadro que condicionou as relações educacionais do ensino público brasileiro, evidenciadas no mapa da figura 1 a seguir, sobre a densidade de domicílios com acesso à Internet. 
Figura 1. Mapa da proporção de domicílios com a utilização de computador para acessar Internet (Brasil).

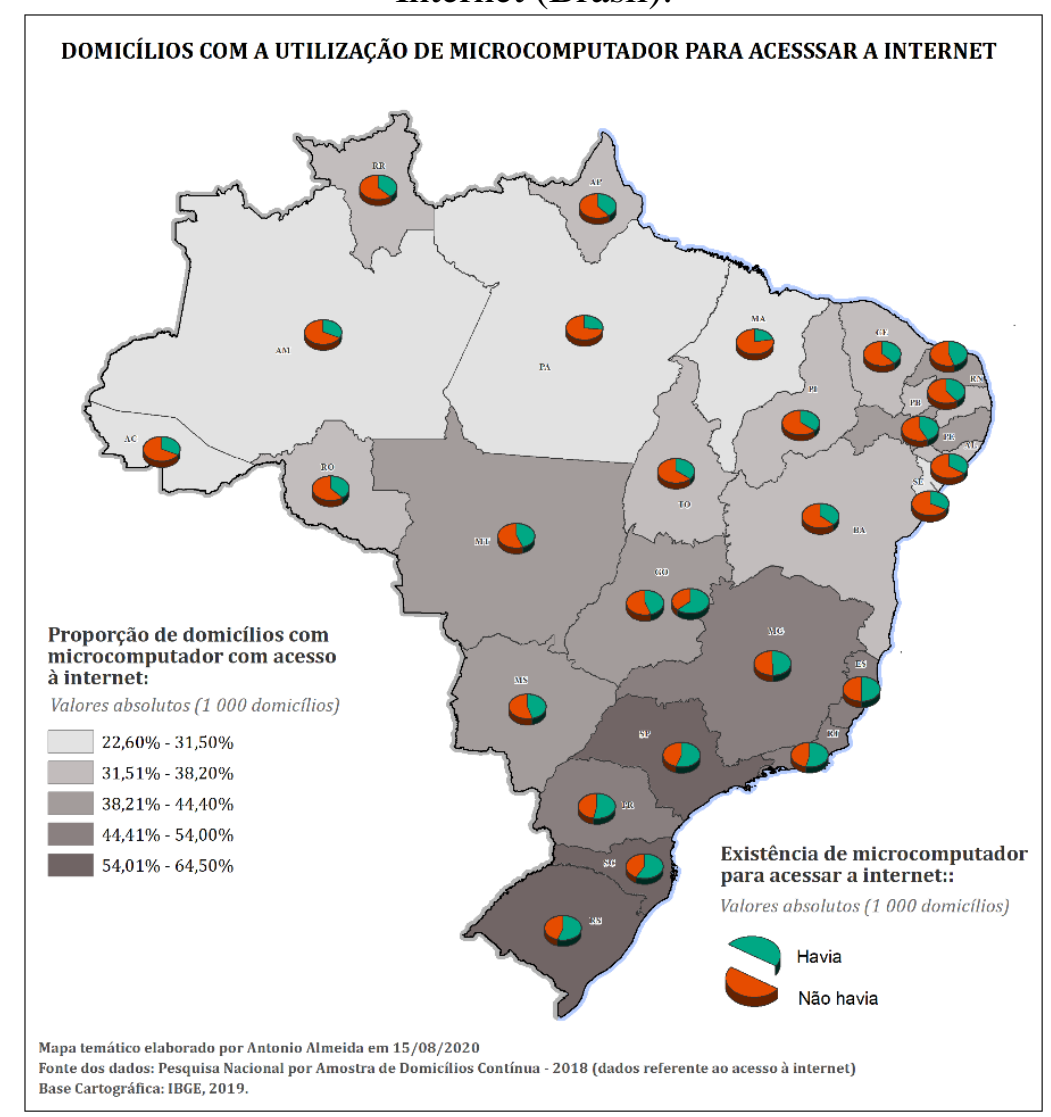

Fonte: PNAD 2018, 2019. Autores: A. Almeida; T. B. de Oliveira.

O mapa evidencia características da diversidade de circunstâncias pelas quais profissionais da educação, alunos e familiares se encontram em relação às necessidades de desenvolver as relações da educação na rede pública no Brasil. Conforme o mapa, apenas 33,6\% dos domicílios alagoanos possui computador com acesso à Internet sendo a média nacional 48,1\%. Dos 67,1\% de domicílios alagoanos que têm acesso à Internet, 20,3\% desse acesso é feito somente por banda larga móvel ${ }^{5}$. Há distribuição bastante desigual no território, de domicílios com posse de computador com acesso à Internet banda larga ilimitada. Nesse sentido, há profunda contradição porque o que se exige como resultado da educação está padronizado, mas as circunstâncias para seu desenvolvimento são diversas num nível geral ruim de condições. O gráfico da figura 2 a seguir demostra mais informações da PNAD 2018 sobre essa capilaridade desigual no território brasileiro.

5 A Internet por banda larga móvel é simbólica sobre as dificuldades e contradições tecnológicas brasileiras. É o tipo de serviço mais popular e o mais caro proporcionalmente. A relativa facilidade tecnológica para o simples acesso se desenrola em inúmeras outras barreiras como a cobertura de banda (3g, 4g, etc.) e o elevado preço, que se baseia no volume de dados digitais acessados (byte). Consequentemente, o tipo de serviço de Internet utilizado pela maioria dos estudantes brasileiros é caro e limitado econômica e socialmente (dada hegemonia do smartphone como principal ferramenta). 
Notas sobre a educação por tecnologias digitais da informação e comunicação na pandemia da covid-19 à luz da geografia

Figura 2. Gráfico do acesso à Internet e posse de computador no domicílio (Brasil)

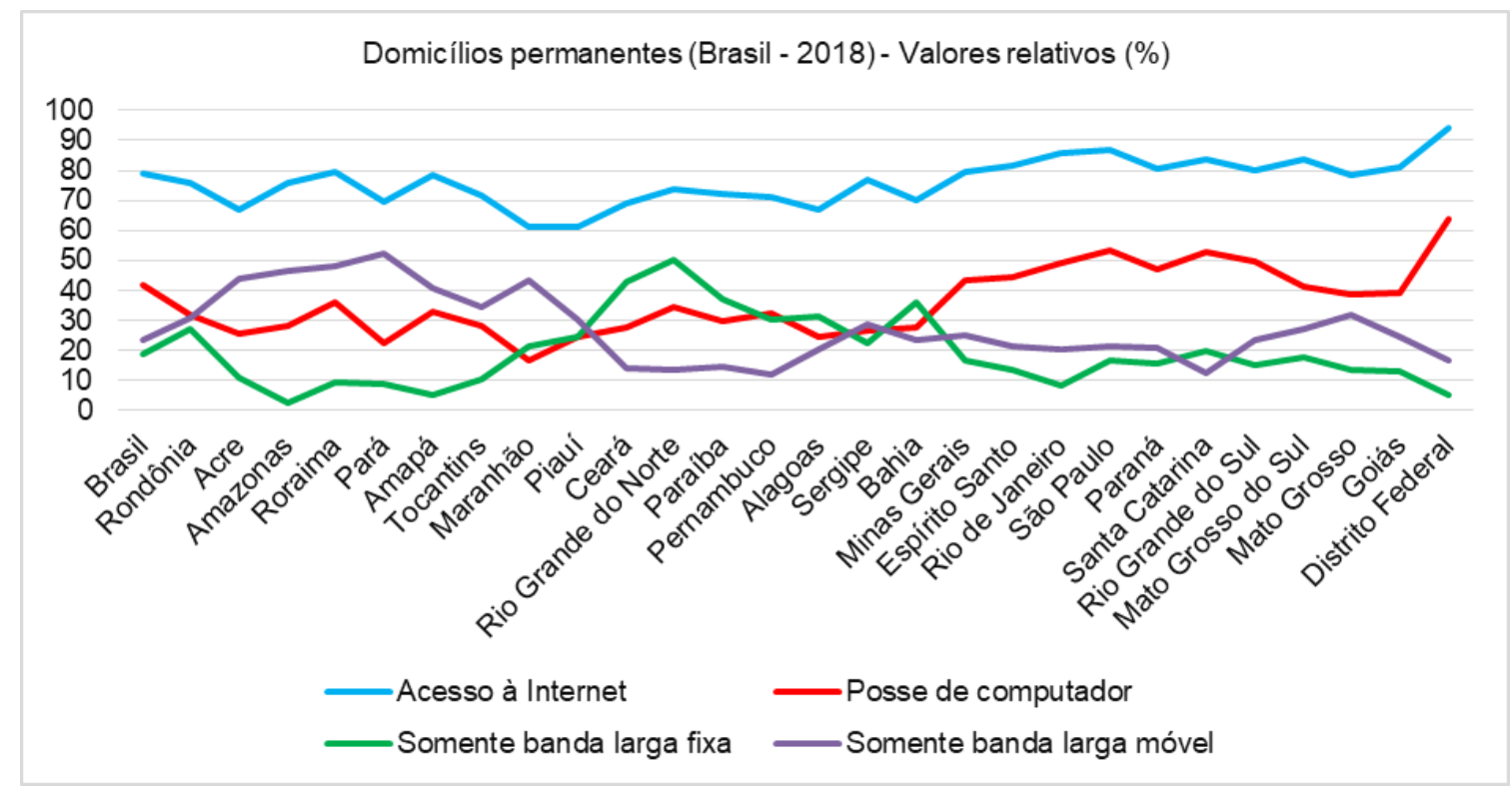

Fonte: PNAD 2018, 2019. Elaboração: autor.

No gráfico, a abrupta oscilação das linhas revela a desigualdade de acesso a essas TDICs no Brasil. Percebe-se ainda, com base nos dados sobre acesso à Internet somente por banda larga fixa ou somente por móvel que, nos domicílios há combinação das duas formas de acesso. Os dados da PNAD ainda revelam que há cerca de 53 milhões de pessoas que não acessam Internet no Brasil. Além disso, há retração da posse de microcomputador nas duas escalas, o que implica inclusão digital incompleta e em grande medida restrita ao uso de smartphone para a maioria da população.

O mapa e o gráfico ainda revelam que a distribuição dessas TDICs no território nacional reproduz a organização espaço-tempo que perpetua a divisão territorial do trabalho no Brasil. O desenvolvimento das telecomunicações possui no seu processo, traço decisivo marcado pela busca por modernização (integração nacional) tendo as firmas como foco, porém excluindo a maioria da população (SANTOS; SILVEIRA, 2008, p. 79). Desse modo, desde o telégrafo ao satélite, houve num primeiro momento (início do século XX) um esforço de difusão que privilegiava as regiões metropolitanas. Contudo, a formação da Região Concentrada (ibid., p. 268) na segunda metade do século XX consolida a densificação das técnicas de comunicação nesta região, principalmente as metrópoles São Paulo e Rio de Janeiro.

Nesse sentido, identifica-se no mapa, maior concentração da proporção de domicílios e da existência de microcomputador para acessar Internet - TDICs elementares na educação - no meio sul do Brasil (Região Concentrada e Centro-Oeste). No gráfico, observa-se esse padrão 
na curva ascendente da posse doméstica de microcomputador nos estados da Região Concentrada e Centro-Oeste em relação aos demais. Da mesma forma, o acesso à Internet é maior nestas regiões. Isso pode indicar maior capacidade de consumo dessas populações, mas também melhor infraestrutura da rede de Internet banda larga, que forma o elo entre as TDICs.

Essa indicação também pode ser entendida nos outros dois dados do gráfico. Ou seja, o acesso à Internet "somente por banda larga móvel" ou "somente por fixa", muito baixo em relação ao dado "acesso à Internet" na Região Concentrada, aponta uso combinando os dois tipos, que pode decorrer de maior capacidade consumo/infraestrutura. Enquanto que na Região Amazônia, o processo de divisão territorial do trabalho, combinado com as características naturais podem ser fatores de influência na organização da infraestrutura, submetendo essa população ao acesso majoritário "somente por banda larga móvel”.

A posse doméstica de equipamentos adequados para se desenvolver processo ensino/aprendizagem está além da simples posse de smartphone com plano de Internet de dados. Aparelhos portáteis como smartphone ou tablet, cada vez mais cumprem funções antes restritas ao microcomputador, todavia possuem desenho e ergonomia para operacionalizar diferentes níveis de ações. Para fins de educação esses equipamentos têm muitas limitações.

Percebe-se que na verdade, não há inclusão digital plena no Brasil, porque não há homogeneidade no acesso às TDICs. Embora as ferramentas constituam um paradigma técnico, existem muitas nuances, desde proporção de usuários em meio rural e urbano ao tipo e atualidade do equipamento, ambiente adequado ao estudo, acesso à Internet banda larga ilimitada, entre outras. Essa diversidade de circunstâncias condiciona a qualidade do fim que se busca.

As TDICs são elementos essenciais da matriz do sistema de objetos e ações que estrutura o meio técnico atual e traduzem uma extensão geográfica deste período. "A ação é tanto mais eficaz quanto os objetos são mais adequados. Então, à intencionalidade da ação se conjuga a intencionalidade dos objetos e ambas são, hoje, dependentes da respectiva carga de ciência e de técnica presente no território" (SANTOS, 2008a, p. 94). Embora seja hegemônico o discurso da globalização tecnológica e da inclusão digital, a difusão não pode ser homogeneizada no espaço pela configuração econômica vigente no Brasil. O uso do território ocorre de forma desigual e os lugares se modificam em ritmos diferentes no espaço. 
Notas sobre a educação por tecnologias digitais da informação e comunicação na pandemia da covid-19 à luz da geografia

\section{A FUNÇÃO DA ESCOLA E AS TDICS}

Embora a possibilidade de acessar informações seja extensa, parece que nossa sociedade ainda não aprendeu a fazer ou, possivelmente, o que esteja acontecendo seja mesmo aquilo que se espera que aconteça, considerando as circunstancias que já foram analisadas neste texto. Um dado curioso é o índice da pesquisa Perigos da Percepção (IPSOS, 2018), vulgarmente chamado de "índice da ignorância" em que o Brasil aparece com frequência nas edições, entre os cinco países onde há mais falta de conhecimento sobre a sua própria realidade social.

Um fenômeno clínico cada vez mais presente, a Síndrome da Fadiga da Informação ou o cansaço da informação (HAN, 2018, p.104), tem se revelado um problema ao desenvolvimento humano. Este autor analisa que "um dos principais sintomas da SFI é o estupor das capacidades analíticas. Justamente a capacidade analítica constitui o pensamento. O excesso de informação faz com que o pensamento definhe." (ibid., p. 105).

As pessoas têm acesso a muita informação de muitas fontes e de maneira difusa ao mesmo tempo que são também antenas transmissoras, produtoras e repetidoras dessas informações. Os lugares são núcleos de concentração e difusão de informações, mas como analisado antes, estão tutelados pelo sistema econômico. Além disso, como sabemos se essas informações produzem conhecimento? E essa informação é útil? Ou ainda, é a informação para o desenvolvimento social realmente necessário? As informações, que são difusas e são fragmentos, são pedaços recebidos como definitivos, acabados, que não são analisados ou compreendidos. Mas não se faz nada com fragmentos. São fragmentos.

O contato das pessoas e a prática de utilização das TDICs tem-se realizado de forma individual e aleatória sem aprendizado na escola e quando ocorre é escasso e inadequado pois, em geral, o que se pretende é a instrumentalização decorrente das características educacionais demostradas antes.

Esse é um exemplo de problema comum da realidade de uso das TDICs na educação, mas é ainda mais grave a ênfase que se dá à necessidade de incorporação das inovações tecnológicas apenas para fins didáticos, ou seja, o uso de tecnologias apenas como ferramentas. Conforme Dowbor (2013, p. 4), 
As tecnologias em si não são ruins. Fazer mais coisas com menos esforço é positivo. Mas as tecnologias sem a educação, conhecimentos e sabedoria que permitam organizar o seu real aproveitamento, levam-nos apenas a fazer mais rápido e em maior escala os mesmos erros. Achávamos que o essencial para desenvolver o país seria criar fábricas e bancos. Hoje constatamos que sem os conhecimentos e a organização social correspondentes, construímos uma modernidade com pés de barro, um luxo de fachada.

Nesse sentido, um problema da educação é o objetivo que se dá à educação enfatizando o uso de TDICs. A contradição em que se encontra a educação é de um lado a desigualdade estrutural, inclusive de acesso às novas tecnologias e do outro, o objetivo que se quer alcançar com o atual modelo de educação.

A Constituição brasileira versa no Artigo 205, e dela ascende as normas da educação, que:

A educação, direito de todos e dever do Estado e da família, será promovida e incentivada com a colaboração da sociedade, visando ao pleno desenvolvimento da pessoa, seu preparo para o exercício da cidadania e sua qualificação para o trabalho (BRASIL, 2016).

Note-se que ao final do artigo, pode-se identificar três objetivos embrionários da normatização da educação brasileira. Já se destacou o terceiro, que como demonstrado, na prática tem sido a principal função do sistema de educação. O segundo é, na verdade, parte deste último, pois exercer cidadania num Estado capitalista é cumprir as funções determinadas pelo sistema econômico.

Como explica Milton Santos em “O Espaço do Cidadão” (2012, p. 25), o processo pelo qual passou o Brasil no século XX - que tem o ciclo da internacionalização da indústria brasileira como força motriz - formou um tipo específico de cidadania, a não-cidadania:

Em nenhum outro país foram assim contemporâneos e concomitantes processos como a desruralização, as migrações brutais desenraizadoras, a urbanização galopante e concentradora, a expansão do consumo de massa, o crescimento econômico delirante, a concentração da mídia escrita, falada e televisionada, a degradação das escolas, a instalação de um regime repressivo com a supressão dos direitos elementares dos indivíduos, a substituição rápida e brutal, o triunfo, ainda que superficial, de uma filosofia de vida que privilegia os meios materiais e se despreocupa com os aspectos finalistas da existência e entroniza o egoísmo como lei superior, porque é o instrumento da buscada ascensão social. Em lugar do cidadão formou-se um consumidor, que aceita ser chamado de usuário.

Essa territorialização brasileira, possivelmente esquizofrênica, instituiu socialmente, e a escola é parte disso, não uma formação cidadã humana, mas uma cidadania obediente ao sistema econômico exploratório. Visto que, 
Notas sobre a educação por tecnologias digitais da informação e comunicação na pandemia da covid-19 à luz da geografia

[...] onde o indivíduo também é cidadão, pode desafiar os mandamentos do mercado, tornando-se um consumidor imperfeito, porque insubimisso a certas regras impostas de fora dele mesmo. Onde não há o cidadão, há o consumidor mais-que-perfeito. É o nosso caso (ibid. p. 56).

Contudo, a forma como o espaço vem se configurando - meio técnico-científicoinformacional - e a sociedade conformada por este processo, a ascensão das TDICs nos permite com certa prudência, acreditar que são a possibilidade de construção de um autêntico modelo de cidadania que possa mudar a lógica de servidão capitalista e isso pode ocorrer a partir da educação. Um modelo de educação em que

Não se trata de buscar apenas a eficácia dos gestos. A eficácia dos gestos pode levar ao mais ter, mas o que nós devemos buscar, na formação dos jovens, é o mais ser. A noção de tecnicidade amplia a ideia dessa relação entre a tecnicidade e o fazer, quando deveria conduzir ao debate entre tecnicidade e pensar. Ensinar a fazer é apenas uma dimensão do ensino. A dimensão central é ensinar a ser Homem. O fazer apenas, é uma regressão, um convite à volta à animalidade. Porque os animais também fazem. O que distingue o homem dos animais é a busca de um objetivo, a produção de um projeto. E este é o perigo em que estamos, na tendência atual de produzir instrução e não educação (SANTOS, 1997, p. 8).

A popularização dos equipamentos de informação e comunicação - atualmente simbolizados pela informática e objetos interconectáveis - antes sob posse apenas dos agentes hegemônicos, demonstra a flexibilidade da materialidade desse modelo industrial, pois demandam menos investimento individual para posse e mais inteligência e expertise para utilização, ao contrário das máquinas que demandam investimentos maciços e procedimentos repetitivos que alienam o operador. "Sob condições políticas favoráveis, a materialidade simbolizada pelo computador é capaz não só de assegurar a libertação da inventividade como torná-la efetiva" (SANTOS, 2013, p. 164). A política, sendo o diálogo social, se faz também na escola no processo educacional. Nesse sentido, há a necessidade de que se conceba essa ideia de educação.

A sociedade da informação necessita que a escola seja não mais a escola com postura concentradora de conteúdos que acredita que a sua função é repassar informações e instruir o indivíduo. A sociedade contemporânea precisa de uma escola verdadeiramente humana. A educação deve desenvolver o cidadão humano e não o individualista, objeto submisso ao sistema econômico hegemônico vigente.

A escola desempenha uma função muito simbólica para a sociedade. De forma que o ambiente escolar converge o conteúdo, a importância e as necessidades da educação social em comunhão, em escala local-global e particular-universal que se processam pelo convívio e 
currículo. A escola é a representação do Estado, é a materialização da cidadania, às vezes em muitos lugares disputando apenas com a rede elétrica. É o elemento da paisagem e o local de convívio social que confere existência do indivíduo ao poder público, que confere cidadania cotidiana.

A ação da escola nunca foi tão necessária como no período atual, pois a lógica de desenvolvimento técnico que se estabeleceu produziu uma sociedade cativa das tecnologias. E a profusão de informação que governa o cotidiano, formou um perfil social confuso e desnorteado, pela abrangência de informações que mais confundem do que orientam. Concomitantemente, a financeirização da educação ampliou e criou múltiplos espaços de ensino (ensino à distância, ensino remoto, cursos técnicos e especializados, escolas empresariais, de organizações sociais, etc.).

Acessar informação não é o mesmo que adquirir conhecimento. A informação é aquilo que chega ao indivíduo, mas conhecimento é aquilo que o ser interpreta e processa como algo proveitoso ao seu processo cognitivo. E a escola de ensino básico é o local capaz de desempenhar essa função de forma mais eficiente por seu potencial caráter universalizante. Dessa forma, a escola precisa ser uma articuladora dos espaços de conhecimento (DOWBOR, 2013, p. 21) e ensinar a aprender e apreender a necessidade de formação humana para que, inclusive, por exemplo, a pessoa possa distinguir conhecimento técnico procedimental de conhecimento humano com vistas à formação cidadã que vá além do capital (MÉSZÁROS, 2008). A cidadania que se precisa constituir, que possibilita uma atitude crítica ao modelo técnico que governa a sociedade, "impede que a instrução se faça sem a companhia da educação" (SANTOS, 1997, p. 8).

Uma educação que possa romper com a lógica preexistente que vem moldando a sociedade ao longo do desenvolvimento do sistema econômico capitalista, que já deu inúmeras provas de sua perversidade. E

[...] é por isso que hoje o sentido da mudança educacional radical não pode ser senão o rasgar da camisa de força da lógica incorrigível do sistema: perseguir de modo planejado e consistente uma estratégia de rompimento do controle exercido pelo capital, com todos os meios disponíveis, bem como com todos os meios ainda a ser inventados e que tenham o mesmo espírito (MÉSZÁROS, 2008, p. 35).

Portanto, não é possível reformar a "educação" porque a reforma parte do pressuposto de que se está ajustando as coisas dentro de uma fôrma, em nosso caso à estrutura preexistente do modo de produção capitalista que moldou nosso sistema de educação e que define a 
Notas sobre a educação por tecnologias digitais da informação e comunicação na pandemia da covid-19 à luz da geografia

escolaridade. Isso porque, simplesmente, esse sistema econômico destruirá o mundo como conhecemos. A obviedade desse fato é a essência destrutiva da lógica de consumo infinito que aniquila a diversidade da natureza ao esgotar recursos finitos transformados em lixo e inutilidades. E a necessidade de educação é ajudar salvar a humanidade de si mesma, do sofrimento cotidiano, da volta à animalidade ou do autoextermínio. Nesse sentido, a necessidade é antes de qualquer coisa, uma mudança de essência da ação educacional, do próprio conceito do sistema social de educação onde a função do Estado deveria se limitar a fornecer toda a infraestrutura e as contradições sociais poderiam orientar as necessidades de educação.

\section{CONSIDERAÇÕES FINAIS}

A discussão que se propôs neste trabalho se provou um grande desafio ao longo das consultas aos autores e dos dados encarados. A angústia civilizatória que se constata a partir do entendimento da forma como a sociedade contemporânea se define utilizando a escolarização como ferramenta de reprodução social, impôs ao estudo a compreensão desse processo, analisando o domínio do sistema econômico vigente sobre a organização do Estado, o modelo instituído de cidadania e a organização do sistema escolar.

Da reflexão sobre a função da escola constatou-se que embora a condição técnica esteja sendo usada de maneira a se perpetuar o problemático modelo de sociedade que vigora, as TDICs demonstram condições de serem incorporadas como via à necessária superação para construção de um outro modelo de educação.

A análise dos dados sobre posse e uso de TDICs, principalmente microcomputador e Internet banda larga, revelou a complexidade disfuncional dessas tecnologias aplicadas à educação no Brasil. Mostrou a desigualdade territorial de TDICs enquanto se apresentam como legítima possibilidade de mudança, mas apontou o provável aumento das desigualdades de rendimento educacional em face das circunstâncias pandêmica combinadas com a organização do espaço brasileiro.

Dentre os problemas da educação pode-se destacar dois fundamentais. As dificuldades técnicas que estão alicerçadas na desigualdade socioeconômica, expressa na irregularidade da instrumentalização (acesso às TDICs de forma homogênea e práticas de uso cotidiano como parte do processo educacional). E principalmente, a essência da ação educacional, a função ao qual o modelo de educação busca corresponder, qual seja, a estruturação com base no 
capitalismo como formação social. Além disso, no contexto de isolamento social, esses problemas se agravaram, pois, a desigualdade de inclusão digital aprofunda o distanciamento cognitivo pela ampliação do abismo entre o acesso à informação e transformação desta em conhecimento. Esse processo se materializa no território brasileiro ao potencializar o desenvolvimento desigual e combinado e agravar a diferença de desenvolvimento entre áreas ou setores no Brasil.

Por fim, essas constatações permitiram entender o papel protagonista da educação, da escola e dos professores na sociedade contemporânea a partir das TDICs, pela forma como os lugares podem ser estruturados - ciberespaço. Essa estruturação que permite ampliação das instâncias culturais, políticas e econômicas dos lugares, demostra que os lugares continuam em processo de formação e que existe a possibilidade da criação de um modelo de sociedade que possa superar as mazelas sociais do nosso tempo e construir uma sociedade verdadeiramente humana.

\section{REFERÊNCIAS}

BRASIL. Constituição (1988). Constituição da República Federativa do Brasil: promulgada em 5 de outubro de 1988. Brasília: Edição Administrativa do Senado, 2016.

CENTRO DE INOVAÇÃO PARA A EDUCAÇÃO BRASILEIRA - CIEB. Currículo de referência em tecnologia e computação: da educação infantil ao ensino fundamental. São Paulo: Cieb, 2018.

COSTA, Mariane B. da. As diferentes manifestações da juventude na escola: uma visão dos impasses e das perspectivas. Revista Conjectura, Caxias do Sul, v. 15, n. 1, p. 93 - 105, jan./abr. 2010. Disponível em < http://www.ucs.br/etc/revistas/index.php/conjectura/article/ view/185/176 >. Acesso em 28 de dezembro de 2020.

DOWBOR, Ladislau. A reprodução social. São Paulo: Vozes, 2001. Vo. I. Disponível em: < http://dowbor.org/2001/09/ladislau-dowbor-a-reproducao-social-nova-edicao-em-tresvolumes-vol-i-155-p-out-2002.html/ > . Acesso em 03 de outubro de 2019.

DOWBOR, Ladislau. Tecnologias do conhecimento: os desafios da educação. São Paulo: Vozes, 2013.

DURKHEIM, Émile. Educação e sociologia. Petrópolis: Vozes, 2011.

FERREIRA JR., Amarilio. História da Educação Brasileira: da Colônia ao século XX. São Carlos: Edufscar, 2010.

FUNDAÇÃO GETÚLIO VARGAS - FGV. $3^{\circ}$ Pesquisa anual do uso de TI nas empresas. São Paulo: FGV, 2020. Disponível em: < 
Notas sobre a educação por tecnologias digitais da informação e comunicação na pandemia da covid-19 à luz da geografia

https://eaesp.fgv.br/sites/eaesp.fgv.br/files/u68/fgvcia2020pesti-ppt_0.pdf $>$ Acesso em 16 de agosto de 2020 .

FREIRE, Paulo. Pedagogia do oprimido. 17. ed. Rio de Janeiro: Paz e Terra. 1987.

GARCIA, Adir V; YANNOULAS, Silvia C. Educação, pobreza e desigualdade social. Revista Em Aberto, Brasília, v. 30, n. 99, p. 21-41, maio/ago. 2017. Disponível em: < http://rbepold.inep.gov.br/index.php/emaberto/article/view/3262 >. Acesso em: 17 fev. 2020.

HAN, Byung-Chu. No enxame: perspectivas do digital. Petrópolis: Vozes, 2018.

INEP. Microdados do Exame Nacional do Ensino Médio - ENEM. Brasília: INEP, 2020. Disponível em < https://www.gov.br/inep/pt-br/acesso-a-informacao/dadosabertos/microdados/enem > Acesso em 25 de dez. 2020.

INDICADORES BÁSICOS DE ALAGOAS - Ano 3, n. 3. Maceió: Secretaria de Estado do Planejamento, Gestão e Patrimônio, 2017.

IPSOS. Perigos da Percepção 2018. São Paulo: Ipsos, 2018. Disponível em $<$ https://www.ipsos.com/pt-br/perigos-da-percepcao-2018>. Acesso em 02 agosto de 2019.

LÉVY, Pierre. Cibercultura. 3 Ed. São Paulo: Editora 34, 2010.

MÉSZÁROS, István. A educação para além do capital. 2. ed. São Paulo: Boitempo, 2008.

OECD. Effective Teacher Policies: Insights from PISA. Paris: OECD Publishing, 2018.

ORTEGA Y GASSET, José. Meditação da técnica: vicissitudes das ciências, cacofonia na física. Rio de Janeiro: Livro Ibero-americano Limitada, 1963.

PERRENOUD, Philippe. Dez novas competências para ensinar. Porto Alegre: Artmed, 2000 .

PESQUISA NACIONAL POR AMOSTRA DE DOMICÍLIOS 2017 - PNAD 2017.

Rendimento de todas as fontes. Rio de Janeiro: IBGE, 2018.

PESQUISA NACIONAL POR AMOSTRA DE DOMICÍLIOS 2018 - PNAD 2018. Acesso à internet e à televisão e posse de telefone móvel celular para uso pessoal. Rio de Janeiro: IBGE, 2019.

RELATÓRIO SAEB 2017. Relatório Sistema de Avaliação da Educação Básica 2017. Brasília: INEP, 2019.

RIBEIRO, Carlos A. C. Desigualdade de oportunidades e resultados educacionais no Brasil. Dados Revista de Ciências Sociais, Rio de Janeiro, vol. 54, n. 1, p. 41-87, jan./mar, 2011. Disponível em < http://dados.iesp.uerj.br/artigos/?id=874 >. Acesso em $20 \mathrm{de}$ dez. 2020.

SANTOS, Milton. A Natureza do espaço: técnica e tempo, razão e emoção. 4 ed. São Paulo: Edusp, 2008a. 
SANTOS, Milton. A Técnica em nossos dias: a instrução e a educação. Associação Brasileira de Mantenedoras de Ensino Superior, Brasília, Palestra realizada em 04 de dezembro de 1997.

SANTOS, Milton. O Espaço do cidadão. 7. ed. São Paulo: Edusp, 2012.

SANTOS, Milton. O Espaço dividido: Os dois circuitos da economia urbana dos países subdesenvolvidos. São Paulo: Edusp, 2008b.

SANTOS, Milton. Por uma outra globalização: do pensamento único à consciência universal. 23 ed. Rio de Janeiro: Record, 2013.

SANTOS, Milton; SILVEIRA, María L. O Brasil: território e sociedade no início do século XXI. 12 ed. Rio de Janeiro: Record, 2008.

SAVIANI, Dermeval; DUARTE, Newton. A formação humana na perspectiva históricoontológica. Revista Brasileira de Educação, Rio de Janeiro, v. 15, n. 45, p. 422 433, set./dez., 2010. Disponível em: <http://www.scielo.br/pdf/rbedu/v15n45/02>. Acesso em: 09 ago. 2020.

SAVIANI, Dermeval. Pedagogia histórico-crítica: primeiras aproximações. 11 ed. Campinas: Autores Associados, 2013.

SOARES, Sergei; SÁTYRO, Natália. O impacto da infra-estrutura escolar na taxa de distorção idade-série das escolas brasileiras de ensino fundamental - 1998 a 2005. Brasília: IPEA, 2008.

SOUZA, Everton A. M. de. História da educação no Brasil: o elitismo e a exclusão no ensino. Cadernos da Pedagogia, São Carlos, v. 12, n. 23, p. 15 - 33, jul/dez 2018. Disponível em < http://www.cadernosdapedagogia.ufscar.br/index.php/cp/article/view/1175/416 > . Acesso em 29 de dez. 2020.

TORNAGHI, André J. da C. et al. Tecnologias na educação: ensinando e aprendendo com as TIC: guia do cursista. 2. ed. Brasília: Secretaria de Educação a Distância, 2010.

TROTSKY, L. A História da Revolução Russa. 3 v. Brasília: Senado Federal Conselho Editorial, 2017.

Recebido em 21de fevereiro 2020

Aceito em 01 de fevereiro de 2021

Publicado em 07 de maio de 2021 